\title{
Productivity improvement of AK 103 assembly line
}

\author{
Tadesse Gebray ${ }^{\#}$ and Ashish Thakur"* \\ \#School of Mechanical and Industrial Engineering, Mekelle University, Mekelle \\ "Solid Mechanics and Design Chair, Ethiopian Institute of Technology \\ Received 02 May 2018, Accepted 03 July 2018, Available online 06 July 2018, Vol.8, No.4 (July/Aug 2018)
}

\begin{abstract}
In particular the paper leads to minimize the assembly time and reduction of product cost that is maximized because of wastage due to crack. The objective of this research was to maximize assembly productivity for AK103 at Gafat Armament Industry. The assembly system was analyzed using layout to represent assembly line and table to represent sub-assemblies. The time needed for each process is also studied. By maintaining the idle machineries and introducing continuity of assembly, the current annual capacity of assembly factory can be improved to 3400 products. Design and development of two jigs performed using available technology in industry. The jigs were tested and both jigs work well with some recommended corrections. One method of improving productivity was specifying cause of crack of the components. Study was made on 234 samples at different time for different purpose. For force fitted components, tolerance was also checked taking 3 samples for each fitting components. The other methods used to reduce assembly time were design of new assembly process layout and stating of recommended solutions for inefficient equipments. By appropriate designed layout and recommended corrections of machineries, production capacity may increase from 3400 to 20580 is conceived.
\end{abstract}

Keywords: Assembly lines, assembly factory, crack, AK 103, assembly time

\section{Introduction}

The product AK 103 is improved feature of AK47. AK47 is named after the Russian designer of the product; Avtomat Kalashnikova during Second World War in 1947.AK103 was manufactured and assembled in Gafat Armament Industry (GAI), defense industry managed under Ethiopian Metal Corporation $15 \mathrm{~km}$ far from Bishoftu. It is about $80 \mathrm{~km}$ from Addis Ababa, producing lightweight armament components. Due to not standard layout of assembly system is not efficient.

Different type of machineries and equipments were used in assembly factory. The machineries that were available in assembly factory are bench drilling, hydropower press, spindle pedestal drilling, polishing, spindle bench drilling, horizontal oil press, disassembly machine, keyway milling, piston assembly, buff grinding, position frame assembly, barrel cleaning, oil pressing, disassembly $\mathrm{m} / \mathrm{c}$, compressed jig, panthograph (copying), pedestal drilling, hydro power press, circular grinding, tool grinding (polisher), buff grinding, copy milling, manual press and hoist.

\section{Literature Review}

In every industry assembly line layout design is important task [S.S.Kuber et.al, 2014], which are affects

*Corresponding author's Email: thakurashish1@gmail.com ORCID ID: 0000-0001-9287-700X

DOI: https://doi.org/10.14741/ijcet/v.8.4.7 the productivity of the company. Type of layout selection to develop assembly line is mainly depends on production rate and the demand [Mark Allington et al, 2006], which decides the preferable layout type [Amir J. Khan et.al, 2013].

A good layout can provide real competitive advantage by facilitating material and information flow processes [Mahendra Singh et al, 2012]. Layout involves the allocation of space and arrangement of equipment's in such a manner that overall operating costs are minimized [Mahendra Singh et al, 2012].

In present situation space utilized improperly and the operator and material flow is more, which affecting the productivity. Lean concepts mainly aimed to improve productivity and reduce wastes [Biman das et.al, 2014]. It is therefore important that businesses also focus on the accounting system and measurement methods to change from traditional thinking to lean thinking by accessing data and reports that support lean manufacturing (Maskell\& Kennedy et al, 2007).

In today's fierce competition, productivity is an important factor for a company's success and particularly Sweden is known for its world class development and productivity (Almstrom P. et al, 2007). Integrating of parts and components is one of the ways of reducing of assembly time in design for assembly. To integrate the components, the following three considerations have to be taken into consideration [Boothroyd Dewhurst et al, 2002]. 
One of the most important manufacturing processes of armament is the assembly process that is required when two or more component parts are to be secured together [Daniel E. Whitney et al, 2004]. Ideas and concepts of armament have brought significant improvements in the assembly methods employed in high-volume production [Geoffrey Boothroyd et al, 2005].

The history of assembly process development is closely related to the history of the development of mass-production methods. The pioneers of mass production are also the pioneers of modern assembly techniques. Their ideas and concepts have brought significant improvements in the assembly methods employed in high-volume production [Geoffrey Boothroyd et al, 2005].

Assembly line balancing often has implications for layout improvement.The assembly line is a moving that passes a series of workstations in a uniform time interval called the workstation cycle time (which is also the time between successive units coming off the end of the line).The total work to be performed at a workstation is equal to the sum of the tasks assigned to that workstation [P. R. Olsen et al, 1978].

The concept of interchangeability was crucial to the introduction of the assembly line at the beginning of the 20th century, and has become a ubiquitous element of modern manufacturing [Lee Peterman et al, 2011].

\section{Research Methodology}

In this section, methodologies that are conducted to perform this work are discussed. Descriptions followed to study the current assembly system and to integrate the components of AK 103 in order to reduce the number of components so that to reduce the assembly time. Methodologies such as hardness testing after heat treatment and crack testing for the samples from different manufacturing processes to specify cause of crack are discussed. In addition, methodology for developing of jigs and design of new process layout are also discussed. The research work has looked at reducing assembly time by integrating components.

\subsection{Analyzing Current Assembly System}

To analyze the current assembly process the typical layout and subassemblies; (a) Clarifying the assemblies and components in subassemblies (b) Representing the current assembly process with layout, and (c) Study of the total time needed for each assembly process were initially considered.

Integrating parts and components to reduce assembly time and cost are considered by methods such as;

- Analyzing the machining processes for the parts in time of separated and integrated.

- Model of the integrated part using CATIA software

- By Identifying Cause of Cracks during Assembly, Investigate Material Composition and Inspection of parts at different steps of the process
- Design jigs and fixtures to increase productivity in assembly of components

- Design of new assembly process layout

The equipment's used to manufacture this part were (1) Rotary cutting machine to prepare parts in their designed geometry (2) Arc welding machine to join the prepared components (3) Helical spring coiling machine for spring in the loader and (4) Drill machine for piercing holes.

\subsection{Design of New Assembly Process Layout}

The tool used to design process layout is depicted in flow diagram. In the assembly factory, 54 parts are received from manufacturing factories (investment casting factory and machining factory).

In design of assembly process layout, methods factors such as; capacity of current available equipments, revising of the existing assembly system, time taken for assembly in each process, long time taking process, cause of problems and recommended solutions covered, and new assembly process layout flow diagram is designed.

Having the above considerations, (1) Design of process layout (2) Setting recommendations on improvements of equipment and labor allocation for each stage of assembly line and (3) Analyzing the improvement in terms of cost and assembly time activities were held in improving productivity of assembly.

3.2.1. Drawing: Integrated components drawing was sketched and prepared using CATIA V5. CATIA drawing of separate and integrated components are shown in Fig. 1.
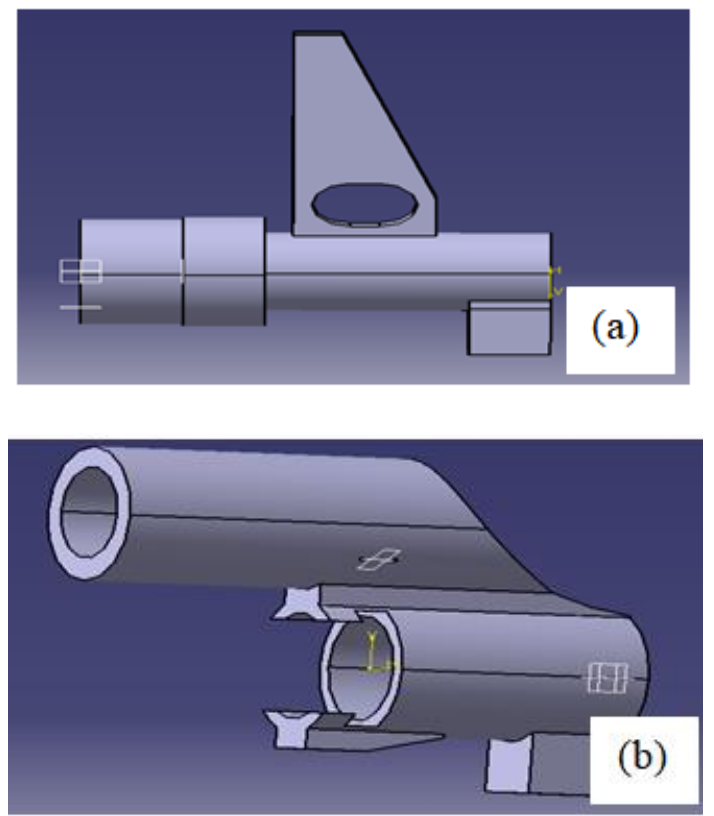

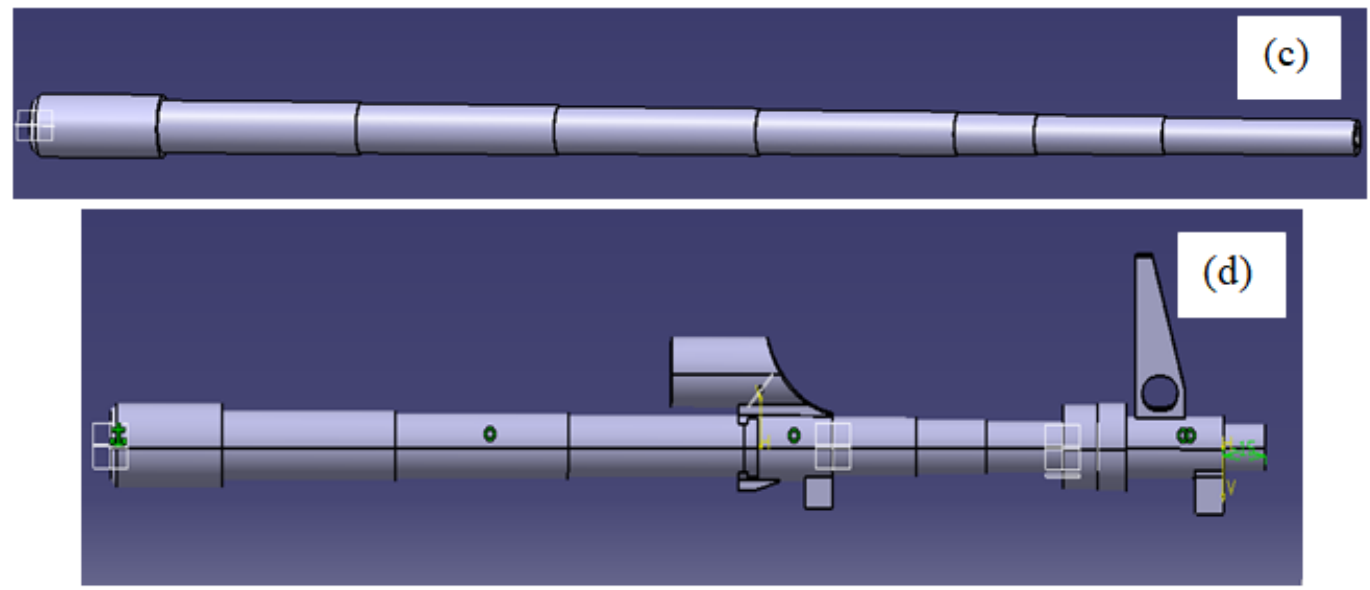

Figure 1: CATIA drawing of separate and integrated components (a) Foresight, (b) gas chamber and (c) barrel (d) integrated

The 53 components received from machining factory should be inspected in first stage of assembly sub grouped in to three groups. These components have to be stored near to assembly line according to the need in assembly line. The 53 components received from manufacturing factories are shown in Table 1 given below.

Table 1: The 53 components received from manufacturing factories

\begin{tabular}{|c|c|c|}
\hline No. & Part name & Part code \\
\hline 1 & Barrel & $11-10$ \\
\hline 2 & Ass. receiver body & Ps11-10 \\
\hline 3 & Muzzle brake & $29-1 c$ \\
\hline 4 & Rear sight base & $11-21$ \\
\hline 5 & Gas chamber & $11-29$ \\
\hline 6 & Foresight base & $11-30$ \\
\hline 7 & Piston frame & $13-1$ \\
\hline 8 & Piston rod & $13-2$ \\
\hline 9 & Ass. Bolt & Ps3-2 \\
\hline 10 & Barrel peg & $11-48$ \\
\hline 11 & Ass. For end ring & Ps11-11 \\
\hline 12 & Eye bolt & $1-42$ \\
\hline 13 & Sight leaf & $22-1 a$ \\
\hline 14 & Foresight pin & $1=32$ \\
\hline 15 & Gas chamber pin & $1-33$ \\
\hline 16 & Rear sight base peg & $1-34$ \\
\hline 17 & Upper hand guard lock & Ps1-6 \\
\hline 18 & Magazine catch pin & $10-13$ \\
\hline 19 & Piston rod pin & Ps3-3 \\
\hline 20 & Hammer & $0-2$ \\
\hline 21 & Trigger & $0-8$ \\
\hline 22 & Sear & $0-9$ \\
\hline 23 & Hammer pin & $0-25 y$ \\
\hline 24 & Muzzle brake spring pin & $20-26$ \\
\hline 25 & Muzzle brake pin & $20-22$ \\
\hline 26 & Ass. Operating rod & Ps14-1 \\
\hline 27 & Operating rod collar & $14-14$ \\
\hline 28 & Receiver cover rivet & $0-22$ \\
\hline 29 & Grip fixing bolt & $10-19$ \\
\hline 30 & Screw driver & $2-1$ \\
\hline 31 & Oiling brush & Yps15 \\
\hline 32 & Cleaning rod & $10-24$ \\
\hline 33 & Ass. Blade & Ps20-34 \\
\hline 34 & Butt stock screw & $5-14$ \\
\hline 35 & Sight leaf spring & $0-23$ \\
\hline 36 & Ass. Upper hand guard & Ps11-12y \\
\hline
\end{tabular}

\begin{tabular}{|c|c|c|}
\hline 37 & Magazine catch & $10-11 \mathrm{y}$ \\
\hline 38 & Magazine catch spring & $0-12$ \\
\hline 39 & Hammer spring & $0-3$ \\
\hline 40 & Safety sear & $0-5$ \\
\hline 41 & Safety sear spring & $0-6$ \\
\hline 42 & Sear spring & $0-10$ \\
\hline 43 & Muzzle brake spring & $11-38$ \\
\hline 44 & Return spring & $4-3$ \\
\hline 45 & Operating rod front part & $14-5$ \\
\hline 46 & Receiver cover & $10-1 \mathrm{y}$ \\
\hline 47 & Receiver cover catch & $20-21$ \\
\hline 48 & Muzzle cup & Yps1-1 \\
\hline 49 & Acc. Case & Y1-1 \\
\hline 50 & Ass. Magazine body & Ps17-1 \\
\hline 51 & Butt stock & b-25 \\
\hline 52 & Lower hand guard & Ps16-1a \\
\hline 53 & Ass. Hand grip & Ps-18 \\
\hline \multicolumn{2}{|c|}{} \\
\hline
\end{tabular}

Grouping of all components for group 1, 2 and 3 assemblies are shown in Table 2 given below.

Table 2: Grouping of the components

Components of group 1 assemblies

\begin{tabular}{|c|c|c|}
\hline No. & Part name & Part code \\
\hline 1 & Barrel & $11-10$ \\
\hline 2 & Ass. receiver body & Ps11-10 \\
\hline 3 & Rear sight base & $11-21$ \\
\hline 4 & Gas chamber & $11-29$ \\
\hline 5 & Foresight base & $11-30$ \\
\hline 6 & Barrel peg & $11-48$ \\
\hline 7 & Ass. For end ring & Ps11-11 \\
\hline 8 & Sight leaf & $22-1 \mathrm{a}$ \\
\hline 9 & Upper hand guard lock & Ps1-6 \\
\hline
\end{tabular}

Components of group 2 assemblies

\begin{tabular}{|c|c|c|}
\hline No. & Part name & Part code \\
\hline 1 & Piston frame & $13-1$ \\
\hline 2 & Piston rod & $13-2$ \\
\hline 3 & Foresight pin & $1=32$ \\
\hline 4 & Gas chamber pin & $1-33$ \\
\hline 5 & Rear sight base peg & $1-34$ \\
\hline 6 & Magazine catch pin & $10-13$ \\
\hline 7 & Piston rod pin & Ps3-3 \\
\hline 8 & Butt stock screw & $5-14$ \\
\hline 9 & Sight leaf spring & $0-23$ \\
\hline 10 & Ass. Upper hand guard & Ps11-12y \\
\hline 11 & Magazine catch & $10-11 \mathrm{y}$ \\
\hline 12 & Magazine catch spring & $0-12$ \\
\hline
\end{tabular}


Components of group 3 assemblies

\begin{tabular}{|c|c|c|}
\hline No. & Part name & Part code \\
\hline 1 & Hammer & $0-2$ \\
\hline 2 & Trigger & $0-8$ \\
\hline 3 & Sear & $0-9$ \\
\hline 4 & Hammer pin & $0-25 y$ \\
\hline 5 & Muzzle brake spring pin & $20-26$ \\
\hline 6 & Muzzle brake pin & $20-22$ \\
\hline 7 & Ass. Operating rod & Ps14-1 \\
\hline 8 & Operating rod collar & $14-14$ \\
\hline 9 & Receiver cover rivet & $0-22$ \\
\hline 10 & Grip fixing bolt & $10-19$ \\
\hline 11 & Screw driver & $2-1$ \\
\hline 12 & Oiling brush & Yps15 \\
\hline 13 & Cleaning rod & $10-24$ \\
\hline 14 & Ass. Blade & Ps20-34 \\
\hline 15 & Hammer spring & $0-3$ \\
\hline
\end{tabular}

\begin{tabular}{|c|c|c|}
\hline 16 & Safety sear & $0-5$ \\
\hline 17 & Safety sear spring & $0-6$ \\
\hline 18 & Sear spring & $0-10$ \\
\hline 19 & Muzzle brake spring & $11-38$ \\
\hline 20 & Return spring & $4-3$ \\
\hline 21 & Operating rod front part & $14-5$ \\
\hline 22 & Receiver cover & $10-1 \mathrm{y}$ \\
\hline 23 & Receiver cover catch & $20-21$ \\
\hline 24 & Muzzle cup & Yps1-1 \\
\hline 25 & Acc. Case & Y1-1 \\
\hline 26 & Ass. Magazine body & Ps17-1 \\
\hline 27 & Butt stock & b-25 \\
\hline 28 & Lower hand guard & Ps16-1a \\
\hline 29 & Ass. Hand grip & Ps-18 \\
\hline 30 & Ass. Hand grip & Ps-18 \\
\hline
\end{tabular}

3.2.2. Process layout: Process flow layout of assembly for AK-103 is shown in Fig. 2 given below

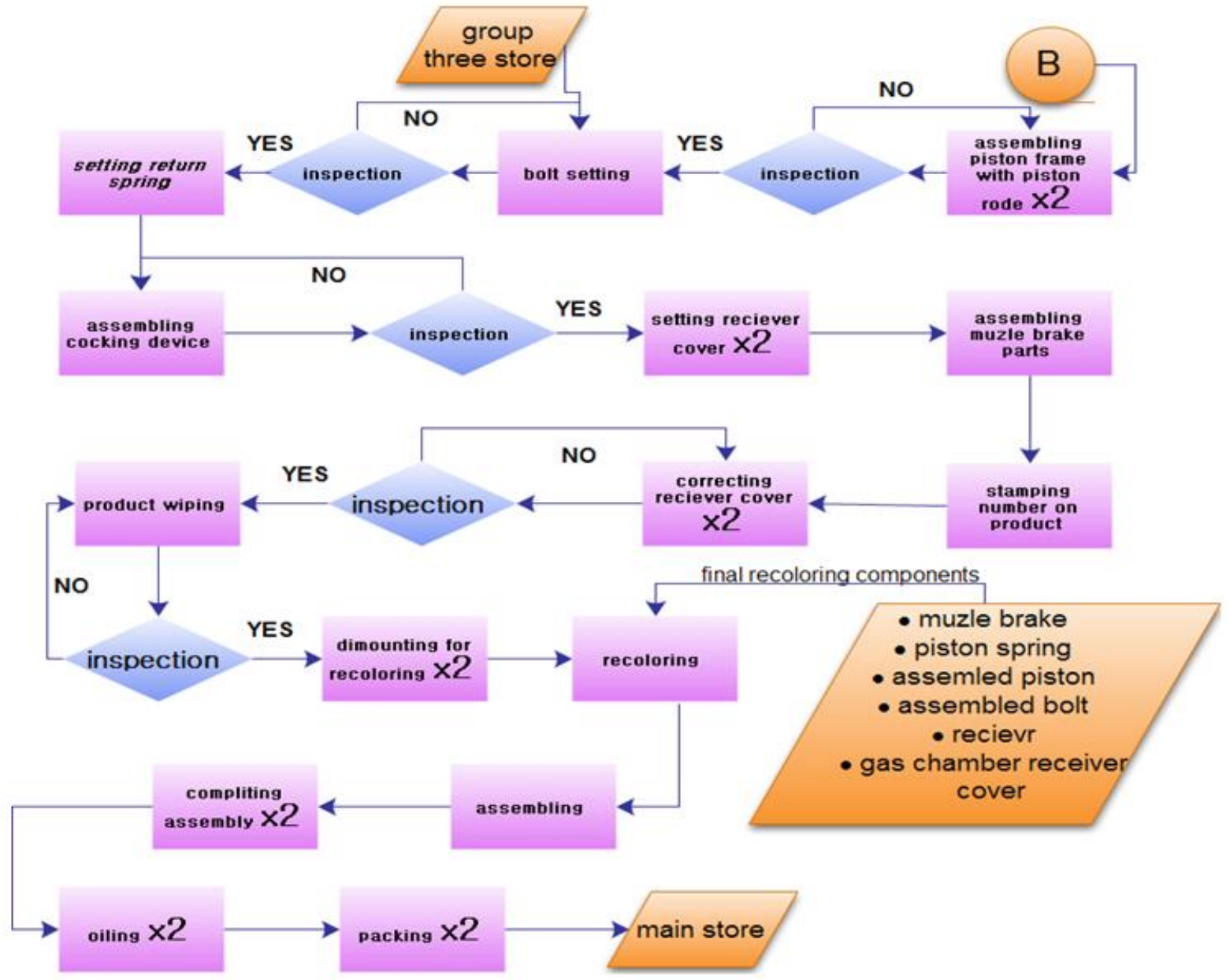

Figure 2: Process flow layout of AK-103 assembly

3.3. Design of Jigs and Fixtures to Increase Productivity in Assembly of Components

Jigs and fixtures are very important to minimize the difficulty and they are necessary in assembly factory. The controlling mechanism of barrel and breech block assembly and spring loader is also used.

The control mechanism was developed due to problem started is in current assembly system. The problem was that when assembling barrel and breechblock by force fitting using horizontal hydraulic machine, they could not show where it is reaching. Because the assembly of barrel and receiver is covered by fixture of hydraulic force fitting machine.

In GAI, the jigs and fixtures found in the factory are inefficient. Efficiency of jigs and fixtures can be improved using available materials and for this two jigs are designed and manufactured. Both jigs are served in 
assembly of barrel and receiver. These two jigs will also have their own contribution in minimizing the problems in assembly of barrel and receiver. The current assembly system of barrel and breechblock is shown in Fig. 3 given below.

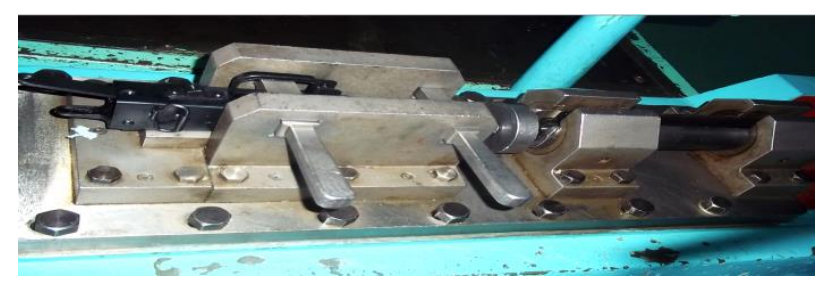

Figure 3: The current assembly system of barrel and breechblock

\subsubsection{Design of Spring Loader for Cartridge Motion Testing}

To design the spring, the light load application (15 kg) and available in industry, the material selected for spring is music wire with diameter of $2.63 \mathrm{~mm}$ and maximum shear stress $490 \mathrm{MPa}$ for average service were considered. CATIA drawing of the assembly of loader is shown in Fig. 4 given below.

Parameters mechanism of spring selection such as; (1) Maximum deflection is the motion of cartridge motion tester that is $130 \mathrm{~mm}(2)$ The weight or load is taken from manual and the figure value is $15 \mathrm{~kg}$ (3) The cross sectional diameter of the wire is $2.63 \mathrm{~mm}$ and (4) internal diameter to be $12 \mathrm{~mm}$, the external diameter will $14.63 \mathrm{~mm}$ were considered.

Considering the data in design, the spring is manufactured in the factory. Then heat treated and made to have recommended property. The case is manufactured as it is shown in the Fig. 4 given below. The working process of the loader is as follows.

1) The number loader and base are connected with telescopic road and spring

2) The base is fixed and the loader is moveable

3) The loader is pulled with two hands

4) It is positioned in the way that the lower extended base connecting the tester

5) The pulled loader is released so that to pull the tester with the desired $15 \mathrm{~kg}$ in its position by using pre extended spring in order to be compressed.

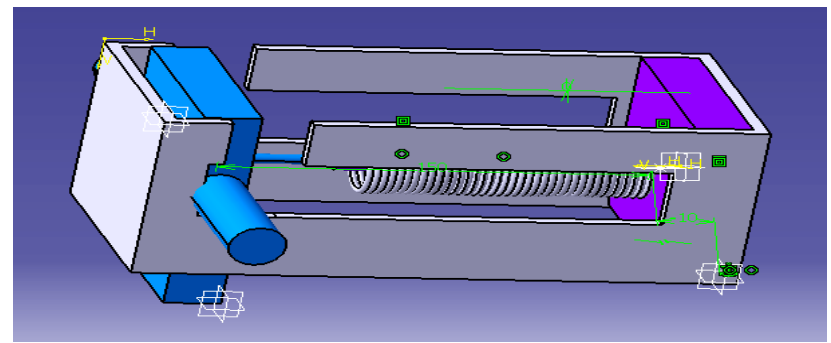

Figure 4: CATIA drawing of the assembly of loader

After manufacturing the spring it is tested with suspending the $15 \mathrm{~kg}$ weight. Then the spring is extent ended for $110 \mathrm{~mm}$. so the building of the case is started depending on that length. Spring loader for testing is shown in Fig. 5 given below.

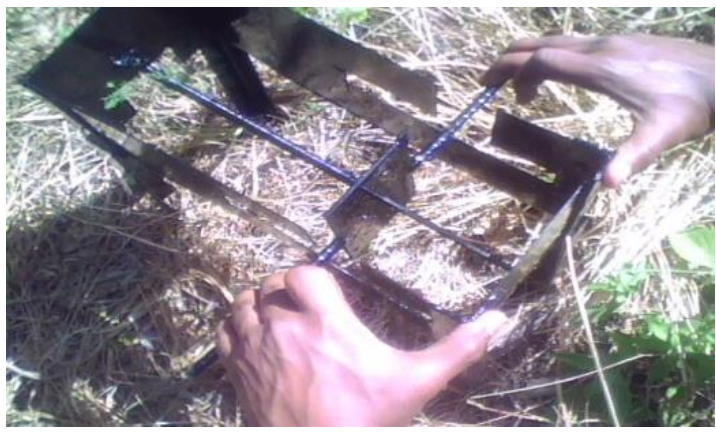

Figure 5: Spring loader

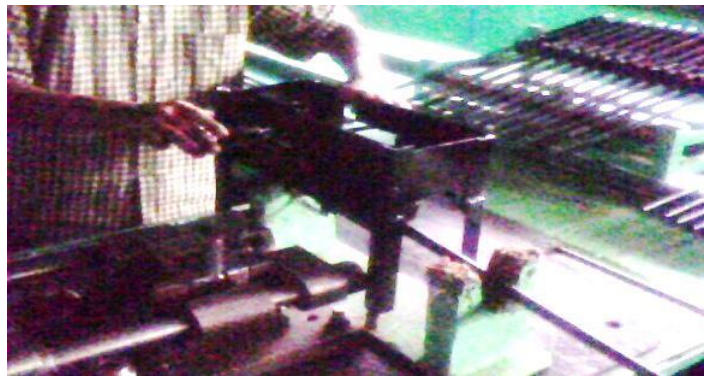

Figure 6: Loader on testing

The loader was tested by fixing it with the table of fixture, then pulling it to the distance of $110 \mathrm{~mm}$ that come from testing of the $15 \mathrm{~kg}$. The loader plate and loading fixture made to be connected. Then realizing the pre extended spring result the desired load. Loader on testing physically handled by operator is shown in Fig. 6 given above.

\subsubsection{Design of controlling mechanism for the range of force fitting distance of barrel and receiver}

Controlling mechanism of force fitting is designed and followed by three mechanisms. Controlling assembly of hydraulic force fit is shown in Fig. 7 given below.

The materials used in this mechanism ware (a) Digital caliper that is numbered with (2) for slider and (1) for digital displayer (b) Moving rod is numbered with (5) (c) Fixed bas is numbered with (3) and (d) Support is numbered with (4)

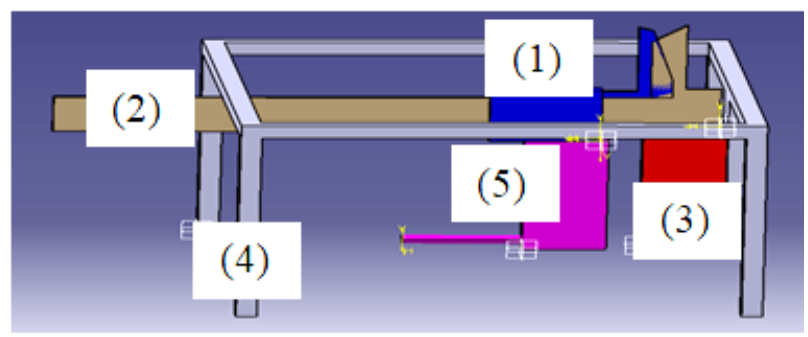

Figure 7: CATIA drawing of hydraulic force fit 


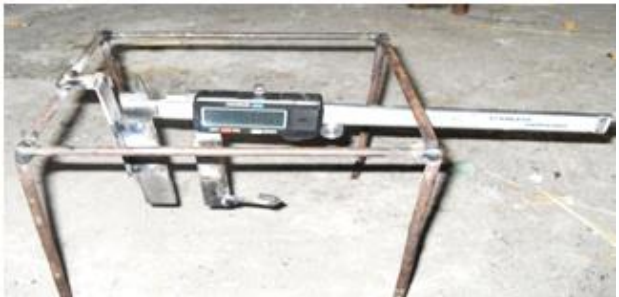

Figure 8: Controlling mechanism

The working principle for the fitting distance indicator is in the following manner.

The caliper is set to zero. The hydraulic machine is started to push the barrel to be fitted in receiver. So the digital displayer of the caliper will be moved reading the distance. After the digital displayer reach at the desired position the foot on the power on will be raised. Controlling mechanism of digital displayer is shown in Fig. 8 given above.

The testing of the control mechanism was done by connecting the end of locator with barrel edge inside breechblock and then the caliper is set to be zero. The hydraulic press machine is started. The caliper was moved in the direction of barrel motion reading the distance it was pushed by barrel. The system of controlling mechanism is shown in Fig. 9 given below.

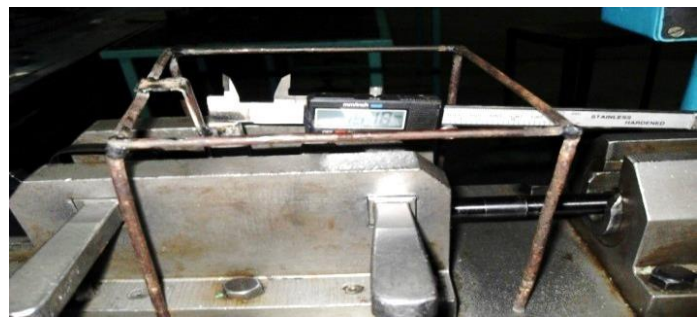

Figure 9: The controlling mechanism loader on testing

\subsubsection{Study of the total time needed for each assembly process}

The time needed in each process is taken from the factory and checked by using timer clock. Beginning from this known data the annual capacity of the factory is estimated by introducing standard continuous assembly system by assigning the workers in each process. Study was made on 234 samples at different time for different purpose.

The capacity of the factory was estimated followed by considerations such as; (a) Seven out of eight working hours are considered as active working time (b) One hour is given for cleaning and other purpose (c) 16 days are given to national days (d) 104 days of week end are also considered as rest.

\subsubsection{Integrating parts and components to reduce assembly time and cost}

To integrate the components it is necessary to analyze the components of AK 103 with the three considerations of design for assembly.
The methods used for this part of research are listed (a) Analyzing the machining processes for the parts in time of separated and integrated, and (b) CATIA software was used to model the integrated part.

\subsubsection{Identifying cause of cracks during assembly}

Frequent cracking of parts during assembly will have significant effect on the overall productivity of assembly. It will result in wastage of time and material. Hence, identifying the real cause of crack in parts is very important. The crack detection methods were mainly used (a) Inspection of parts at different steps of the process (b) Investigation of heat treatment of parts.

\subsubsection{Inspection of parts at different steps of the process}

Magnetic crack testing mechanism is used to inspect crack at different level at Dejen Aviation. This is the method by which bearings of aircraft are inspected in the company. Taking samples from components that are in machining, heat treatment, coloring, assembly and recoloring; crack detection testing is performed. Samples are selected in the processes randomly. Components for magnetic crack testing were taken are shown in Fig. 10 given below.
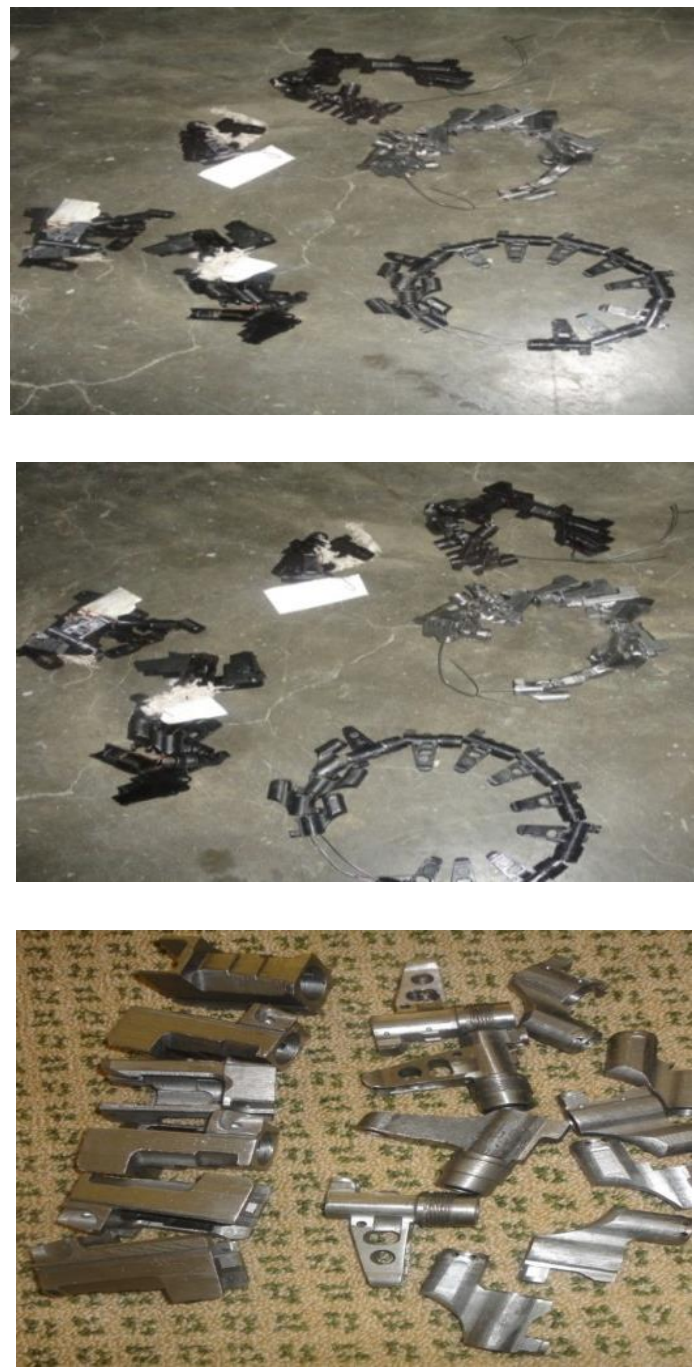


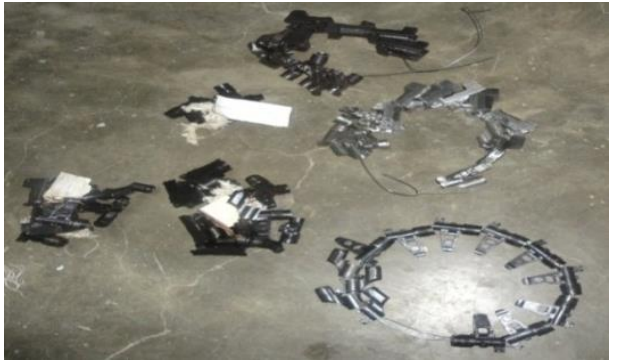

Figure 10: Components for magnetic crack testing

\subsubsection{Effect of assembly system on cause of crack}

Effect of assembly equipment that could be resulted due to vibration of drilling machineries and problem on force fit. The test was conducted for the components to be checked conditioned by (1) if hardness is in the recommended range (2) the components are checked if there was no defects or cracks (3) assembly process is conducted on the components, and finally the components are checked if there is crack due to assembly process are they if any.

In addition to that the dimensions of male and female parts are checked if they are not out of standards. The desired dimensions are taken from manual. Three samples are selected by random method. Measuring of the internal diameter for female and external diameter for male components is taken by using digital caliper. Then deviation of measured value is compared to deviation of manual value.

\section{Results and Discussion}

4.1 Problems and cause of problems for Equipment and Labor allocation for each stage of assembly line

In current assembly system, there are different problems at different stages. The problem of crack in foresight gas chamber and breechblock is also discussed. The time indicated in bracket shows the improvement of assembly time by applying the recommended solutions.

\section{Barrel and receiver assembly (20-5 $\mathrm{min})$}

In GAI there was four group of barrel was manufacturing. The main difference of different group barrel was difference in geometry. Group manufacturing system of barrel result problem in interchangeability in assembly time. This group manufacturing system was avoided and identical interchangeable barrel is made to manufactured. Two jigs will help to minimize the number of problems in barrel and receiver assembly. Barrel and receiver assembly picture is shown in Fig. 11 given below.

\section{Observed Problems}

There are four problems observed in bareel and recover assembly section and namely they are; (1) difficult of assembling barrel and receiver on their correct positioning (2) Barrel and receiver is often idle due to man power (3) Barrel and receiver fitting machine have problem of stacking and providing needed force and, (4) problem on accuracy of barrel and receiver products.

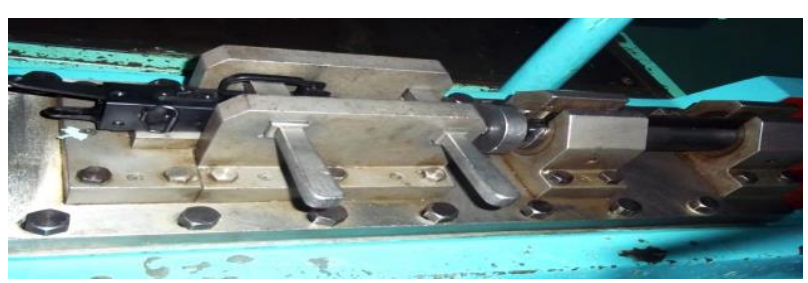

Figure 11: Barrel and receiver assembly

\section{Causes of problem}

The reason for the problems are raised such as; (1) accuracy in barrel and receiver (2) The machinery for force fitting of barrel and receiver has problem and the workers that are assigned in this area often leave the work and it result the assembly system to be idle for long period of time (3) The machine on the assembly has internal maintenance problem.

\section{Receiver body \& barrel fixing pin (20 - 5 min)}

Observed Problems: Problems observed during fixing pin are such as; (1) Breech block and receiver body is assembled by pin. The pin hole is pierced by drill. The pin is assembled by force fit and at this time breech block is often cracked, and (2) the pin is large.

\section{Causes of the problems}

There two causes for breech block crack are; (1) The machine using for drilling shows vibration sign due to long time working and it is difficult to position center in the time of drilling (2) Breech block is not in its HRC when it comes from machine shop, and (3) tolerance and accuracy problem in the assembly parts.

\section{a. Lock and rear sight frame (10-5 $\mathrm{min})$}

Observed Problems: Problems observed in sight frame and they are namely; (1) Lock and rear sight assembly machine is not working (2) Crack on rear sight base.

\section{Causes of problem}

Two problems were raised and these are namely such as: (1) The machine has maintenance problem (2) The product has not desired HRC

b. Foresight frame and gas chamber for fixing pin (20-5 $\min$ )

\section{Problems}

There are couple of problems observed in sight frame and gas chamber and those are such as; (1) Problem of 
keeping the center when we pierce due to vibration of the machinery (2) Jig problem of the machinery (3) drill bit problem (4) After drilling there is need of pin insertion for foresight and gas champers (5) problem on pins accuracy (6) Cracking problem when foresight and gas champers are pierced and (7) cracking at the time of pin insertion

\section{Causes of problem}

The cause of problems are counted and they are namely such as; (1) vibration problem on the machinery (2) problem on jigs due to long time service (3) Break down of drill bit is the main problem and to take out the broken drill bit is time taking (4) The pin insertion is by man power and it is time taking and effort full process (5) Size of pin is much larger than drill bit, so that it difficult to force fit (6) In the time of piercing foresight frame and gas champers there is cracking problem and the cause for this problem is that the parts are not with desired HRC.

\section{c. Sight leaf assembly (25-20 $\mathrm{min})$}

Problem observed during sight leaf assembly was its boring and time taking to adjust sight leaf. Cause of problem exactly were human power adjustment is time taking and it needs large human power.

\section{d. Piston assembly (15-7 min)}

Observed Problems: Problems observed in piston assembly were (1) Piston carrying capacity either being large or smaller (2) If the metal is strong it is difficult the pin to penetrate, and (3)Pistons are not interchangeable

\section{Cause of problem}

Causes of problems were counted such as; (1) Production of piston is not in their desired specifications (2) The metals are beyond the desired HRC (3) If we can keep the specification of piston, there will be increment in interchangeability of piston.

\section{e. Bolt setting (30-5 $\mathrm{min})$}

Prepared drawing of bolt using CATIA software is shown in Fig. 12 given below.

Observed Problems: Four problems were observed during bolt setting and they are as:(1) problem of bolt to fit in its position (2) bolt has variability problem (3) problem on firing pin, and (4) problem on extractor

\section{Causes of problem}

During the bolt stetting causes arise were counted and they are; (1) bolt have very complex geometry the cause of problem in the desired criterion (2) bolts are not uniform when they are produced (3) The basic problem on firing pin is that there is not drill bit for that hole, and (4) problem of extractor is that it is made manually.

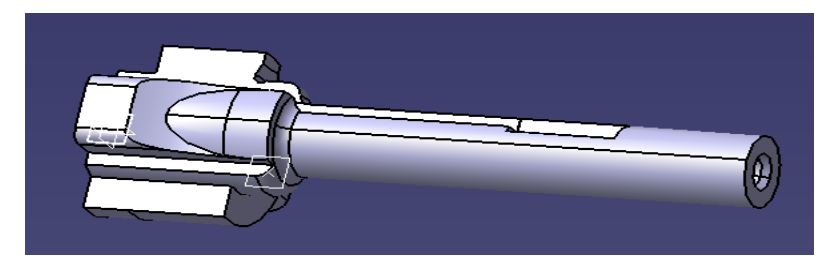

Figure 12: CATIA drawing of bolt

\subsection{Identifying cause of cracks during assembly}

The parts that are wasted due crack are foresight, gas chamber and breech block. There is no crack inspecting equipment in processes. Here are photographs of often cracking components of AK103. They are gas chamber, breech block and foresight (left to right). Components with frequent cracks during assembly are shown in Fig. 13 given below.
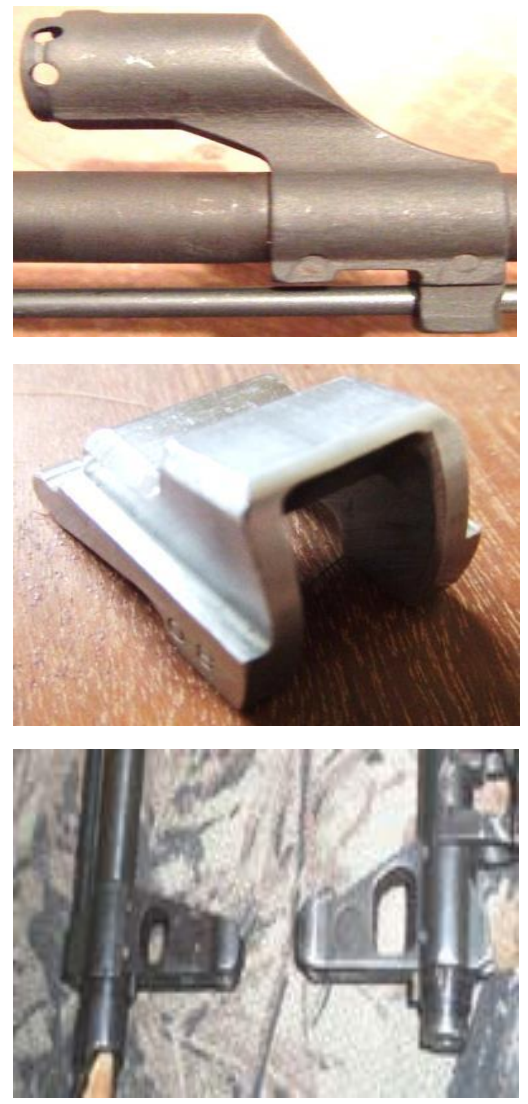

Figure 13: Components with frequent cracks during assembly

Taking the pieces from machining, heat treatment, coloring, assembly and recoloring processes the test of crack detection was conducted on the components using magnetic crack testing mechanism. Crack detection result which is obtained for the components from different processes is shown in Table 3 give below. 
Table 3: Result of crack detection for the components from different processes

\begin{tabular}{|c|c|c|c|c|}
\hline Type of components & Level of process & $\begin{array}{c}\text { Total number of } \\
\text { pieces }\end{array}$ & $\begin{array}{c}\text { number of Crack } \\
\text { detected pieces }\end{array}$ & remark \\
\hline Foresight base & machining & 8 & 0 & \\
\hline Gas chamber & machining & 8 & 0 & \\
\hline Breech block & machining & 8 & 0 & \\
\hline Foresight base & Heat treatment & 8 & 2 & \\
\hline Gas chamber & Heat treatment & 8 & 1 & \\
\hline Breech block & Heat treatment & 8 & 1 & \\
\hline Foresight base & coloring & 8 & 2 & \\
\hline Gas chamber & coloring & 8 & 1 & \\
\hline Breech block & coloring & 8 & 2 & \\
\hline Foresight base & assembly & 8 & 3 & \\
\hline Gas chamber & assembly & 8 & 1 & \\
\hline Breech block & assembly & 8 & 2 & \\
\hline Foresight base & recoloring & 8 & 4 & \\
\hline Gas chamber & recoloring & 8 & 2 & \\
\hline Breech block & recoloring & 8 & 3 & \\
\hline
\end{tabular}

As we can see from table result of crack test the most cracking piece is foresight. Coloring is the process in which most crack is observed. In machining no problem is observed. In fact the stress concentration in previous process can be cause of crack in assembly and recoloring.

\subsection{Investigation of heat treatment of parts}

Crack detecting components by hardness testing are shown in Table 4 given below.

Table 4: Result of Rockwell hardness testing for crack detected components

\begin{tabular}{|c|c|c|c|}
\hline $\begin{array}{c}\text { Type of } \\
\text { components }\end{array}$ & $\begin{array}{c}\text { Total } \\
\text { number of } \\
\text { pieces }\end{array}$ & $\begin{array}{c}\text { number of } \\
\text { pieces out of } \\
\text { HRC result }\end{array}$ & $\begin{array}{c}\text { Range of } \\
\text { Rockwell }\end{array}$ \\
\hline Fore sight & 8 & 5 & $35-42$ \\
\hline Gas chamber & 8 & 3 & $35-42$ \\
\hline Breech block & 8 & 4 & $37-44$ \\
\hline
\end{tabular}

As it can be observed from table half of the crack defected, pieces are out of recommended Rockwell hardness values. Therefore, half of the crack problem is due to problem on heat treatment or inability of keeping recommended hardness value.

As it is surveyed the heat treatment process, there are main problems in keeping manual instructions. So the problem of cracking of the components starts at this stage.

\subsection{Investigation of alkaline coloring process}

To observe effect of chemical on cracking of the components, statistical test was conducted in recoloring process. The following result was obtained. Effect of recoloring process on cracking of the components are shown in Table 5 given below.

Table 5: Effect of recoloring process on cracking of the components

\begin{tabular}{|c|c|c|}
\hline $\begin{array}{c}\text { Component } \\
\text { type }\end{array}$ & $\begin{array}{c}\text { Number of } \\
\text { components tested }\end{array}$ & $\begin{array}{c}\text { Number of } \\
\text { components crack } \\
\text { detected }\end{array}$ \\
\hline Fore sight & 20 & 8 \\
\hline Gas chamber & 20 & 5 \\
\hline Breech block & 20 & 7 \\
\hline
\end{tabular}

From the statistical data results, about $50 \%$ cause of crack is due to problem in heat treatment. Based on statistical experiment made on coloring process, 33\% cause of crack is due to effect of different chemicals in coloring process on stress concentrated components. From the experiment made in assembly process, 10\% cause of crack is the problem in current assembly process and the rest $7 \%$ cause of crack is due to unknown problem on which test cannot be held.

\subsection{Study of the total time needed for each assembly process}

The processes are assembly of barrel and receiver, assembly of lock and rear sight frame, sight leaf assembly, adjustment of aiming line, adjustment of gas chamber position, drilling fixing pin hole for rear sight frame, drilling fixing pin hole for gas chamber, setting fixing pin, machining gas hole, fore end assembly, assembly of magazine catch, assembly of piston frame, bolt setting, assembly of cocking device, setting receiver cover, stamping number of products, correcting receiver cover, disassemble the rifle, cleaning the rifle, assembly of the rifle and packing of the product. Therefore, there is a need of improvement this processes. Total Time taken for assembly of AK 103 is shown in Table 6 given below. There are three symbols in table and the meaning of the symbols is depicted below.

$\mathbf{A}=$ Current Finishing time $(\mathrm{min}), \mathbf{B}=$ total pieces processed/year in one shift, $\mathbf{S} / \mathbf{N}=$ serial number

Detailed result of improvement for assembly time for forty six processing's enlisted in Table 6 given above. As it can be seen in the below Table, the annual capacity of all assembly steps are 20580 and above. Therefore, the minimum annual capacity for improved system is less than the planed 30,000. Annual assembly capacity of improved system is shown in Fig. 14. 
Table 6:Time taken for assembly of AK 103

\begin{tabular}{|c|c|c|c|}
\hline $\mathbf{S} / \mathbf{N}$ & Process name & $\mathbf{A}$ & B \\
\hline 1 & Barrel \& receiver ass. & 20 & 5145 \\
\hline 2 & Recording on certificate & 1 & 102900 \\
\hline 3 & Stamping on receiver & 5 & 20580 \\
\hline 4 & Machining fixing pin hole & 5 & 20580 \\
\hline 5 & Fixing pin ass. & 3 & 34300 \\
\hline 6 & Grooving for extractor & 5 & 20580 \\
\hline 7 & Ass. Lock \&ass. rear sight frame & 10 & 10290 \\
\hline 8 & Ass. Gas chamber \& for end ring & 5 & 20580 \\
\hline 9 & Adj. Gas chamber position & 10 & 10290 \\
\hline 10 & Sight leaf assembly & 25 & 4116 \\
\hline 11 & Adj. Aiming line & 15 & 6860 \\
\hline 12 & Ass. Foresight base & 2 & 51450 \\
\hline 13 & Correcting foresight base & 5 & 20580 \\
\hline 14 & Amending barrel with long gauge & 2 & 51450 \\
\hline 15 & Drilling fixing pin hole for rear sight frame & 6 & 17150 \\
\hline 16 & Drilling fixing pin hole for gas chamber & 10 & 10290 \\
\hline 17 & Setting fixing pin & 20 & 5145 \\
\hline 18 & Amending unsatisfied product & 5 & 20580 \\
\hline 19 & Assembling. Assembled upper hand guard & 5 & 20580 \\
\hline 20 & Writing product no & 5 & 20580 \\
\hline 21 & Machining gas hole & 12 & 8575 \\
\hline 22 & Debarring on gas hole & 2 & 51450 \\
\hline 23 & Dismounting before coloring & 5 & 20580 \\
\hline 24 & Coloring\& inspecting & 5 & 20580 \\
\hline 25 & Receiver wiping \&setting change lever & 5 & 20580 \\
\hline 26 & Ass. sight leaf \&upper hand guard & 5 & 20580 \\
\hline 27 & Replacing sight leaf & 3 & 34300 \\
\hline 28 & Butt stock ass. & 5 & 20580 \\
\hline 29 & Butt stock fixing & 5 & 20580 \\
\hline 30 & Finishing & 3 & 34300 \\
\hline 31 & Fore end ass. & 10 & 10290 \\
\hline 32 & Ass. Magazine catch & 10 & 10290 \\
\hline 33 & Ass. Piston frame & 15 & 6860 \\
\hline 34 & Bolt setting & 30 & 3430 \\
\hline 35 & Replacing bolt after firing & 5 & 20580 \\
\hline 36 & Setting return spring & 3 & 34300 \\
\hline 37 & Ass. Cocking device & 20 & 5145 \\
\hline 38 & Setting receiver cover & 6 & 17150 \\
\hline 39 & Ass. Muzzle brake parts & 5 & 20580 \\
\hline 40 & Stamping no. of products & 10 & 10290 \\
\hline 41 & Correcting receiver cover & 7 & 14700 \\
\hline 42 & Disassemble the rifle & 7 & 14700 \\
\hline 43 & Coloring & 2 & 51450 \\
\hline 44 & Cleaning the rifle & 10 & 10290 \\
\hline 45 & Ass. The rifle & 7 & 14700 \\
\hline 46 & Punch the hand grip & 1 & 102900 \\
\hline 47 & Oiling & 1 & 102900 \\
\hline 48 & packing & 10 & 10290 \\
\hline
\end{tabular}

\subsection{Analysis of improvement on assembly time and cost}

\section{A. Improvement of time}

By applying, the recommended solutions and the layout, there will be reduction of time. Improvement in assembly time is shown in Table 7 given below. Nomenclatures of the concepts on the table are listed below.

A: Current finishing time (min), B: total pieces processed/year in one shift, C: New Finishing time (min), D: Recommended number of assembly lines, E: total pieces processed per year, F: One line \& one shift assembly process, G: Two line \& one shift assembly process.

This graph from Fig. 14 shows the processes of assembly versus annual production capacity. The horizontal line in between 20000 and 40000 represents the plan of the industry that is 30000 annual production capacities. As it is shown in the above graph, most of the assembly processes are below the planed capacity that is 30000 . There are some assembly processes near to zero line representing annual assembly productivity of about 500 . 
Table 7: Result of improvement for assembly time

\begin{tabular}{|c|c|c|c|c|c|c|c|}
\hline \multirow{2}{*}{$\mathrm{S} / \mathrm{N}$} & \multirow{2}{*}{ Process name } & \multirow{2}{*}{ A } & \multirow{2}{*}{ B } & \multirow{2}{*}{$\mathrm{C}$} & \multirow{2}{*}{$\mathrm{D}$} & \multicolumn{2}{|c|}{$\mathrm{E}$} \\
\hline & & & & & & $\mathrm{F}$ & G \\
\hline 1 & Barrel \& receiver ass. & 20 & 5145 & 5 & 1 & 20580 & 41160 \\
\hline 2 & Recording on certificate & 1 & 102900 & 1 & 1 & 102900 & 205800 \\
\hline 3 & Stamping on receiver & 5 & 20580 & 5 & 1 & 20580 & 41160 \\
\hline 4 & Machining fixing pin hole & 5 & 20580 & 5 & 1 & 20580 & 41160 \\
\hline 5 & Fixing pin ass. & 3 & 34300 & 3 & 1 & 34300 & 68600 \\
\hline 6 & Grooving for extractor & 5 & 20580 & 5 & 1 & 20580 & 41160 \\
\hline 7 & Ass. Lock \&ass. rear sight frame & 10 & 10290 & 5 & 1 & 20580 & 41160 \\
\hline 8 & Ass. Gas chamber \& for end ring & 5 & 20580 & 5 & 1 & 20580 & 41160 \\
\hline 9 & Adj. Gas chamber position & 10 & 10290 & 5 & 1 & 20580 & 41160 \\
\hline 10 & Sight leaf assembly & 25 & 4116 & 20 & 4 & 20580 & 41160 \\
\hline 11 & Adj. Aiming line & 15 & 6860 & 5 & 1 & 20580 & 41160 \\
\hline 12 & Ass. Foresight base & 2 & 51450 & 2 & 1 & 51450 & 102900 \\
\hline 13 & Correcting foresight base & 5 & 20580 & 5 & 1 & 20580 & 41160 \\
\hline 14 & Amending barrel with long gauge & 2 & 51450 & 2 & 1 & 51450 & 102900 \\
\hline 15 & Drilling fixing pin hole for rear sight frame & 6 & 17150 & 6 & 2 & 34300 & 68600 \\
\hline 16 & Drilling fixing pin hole for gas chamber & 10 & 10290 & 5 & 1 & 20580 & 41160 \\
\hline 17 & Setting fixing pin & 20 & 5145 & 5 & 1 & 20580 & 41160 \\
\hline 18 & Amending unsatisfied product & 5 & 20580 & 5 & 1 & 20580 & 41160 \\
\hline 19 & Assembling. Assembled upper hand guard & 5 & 20580 & 5 & 1 & 20580 & 41160 \\
\hline 20 & Writing product no & 5 & 20580 & 5 & 1 & 20580 & 41160 \\
\hline 21 & Machining gas hole & 12 & 8575 & 12 & 3 & 25725 & 51450 \\
\hline 22 & Debarring on gas hole & 2 & 51450 & 2 & 1 & 51450 & 102900 \\
\hline 23 & Dismounting before coloring & 5 & 20580 & 5 & 1 & 20580 & 41160 \\
\hline 24 & Inspecting colored components & 5 & 20580 & 5 & 1 & 20580 & 41160 \\
\hline 25 & Receiver wiping \&setting change lever & 5 & 20580 & 5 & 1 & 20580 & 41160 \\
\hline 26 & Ass. sight leaf \&upper hand guard & 5 & 20580 & 5 & 1 & 20580 & 41160 \\
\hline 27 & Butt stock ass. & 5 & 20580 & 5 & 1 & 20580 & 41160 \\
\hline 28 & Butt stock fixing & 5 & 20580 & 5 & 1 & 20580 & 41160 \\
\hline 29 & Finishing & 3 & 34300 & 3 & 1 & 34300 & 68600 \\
\hline 30 & Fore end ass. & 10 & 10290 & 10 & 2 & 20580 & 41160 \\
\hline 31 & Ass. Magazine catch & 10 & 10290 & 5 & 1 & 20580 & 41160 \\
\hline 32 & Ass. Piston frame & 15 & 6860 & 7 & 2 & 29400 & 58800 \\
\hline 33 & Bolt setting & 30 & 3430 & 5 & 1 & 20580 & 41160 \\
\hline 34 & Setting return spring & 3 & 34300 & 3 & 1 & 34300 & 68600 \\
\hline 35 & Ass. Cocking device & 20 & 5145 & 5 & 1 & 20580 & 41160 \\
\hline 36 & Setting receiver cover & 6 & 17150 & 6 & 2 & 34300 & 68600 \\
\hline 37 & Ass. Muzzle brake parts & 5 & 20580 & 5 & 1 & 20580 & 41160 \\
\hline 38 & Stamping no. of products & 10 & 10290 & 10 & 2 & 20580 & 41160 \\
\hline 39 & Correcting receiver cover & 7 & 14700 & 7 & 2 & 29400 & 58800 \\
\hline 40 & Disassemble the rifle & 7 & 14700 & 7 & 2 & 29400 & 58800 \\
\hline 41 & Inspecting Colored pieces & 2 & 51450 & 2 & 1 & 51450 & 102900 \\
\hline 42 & Cleaning the rifle & 10 & 10290 & 10 & 2 & 20580 & 41160 \\
\hline 43 & Ass. The rifle & 7 & 14700 & 7 & 2 & 29400 & 58800 \\
\hline 44 & Punch the hand grip & 1 & 102900 & 1 & 1 & 102900 & 2058000 \\
\hline 45 & Oiling & 1 & 102900 & 1 & 1 & 102900 & 205800 \\
\hline 46 & packing & 10 & 10290 & 10 & 2 & 20580 & 41160 \\
\hline & & & & & 61 & & \\
\hline
\end{tabular}

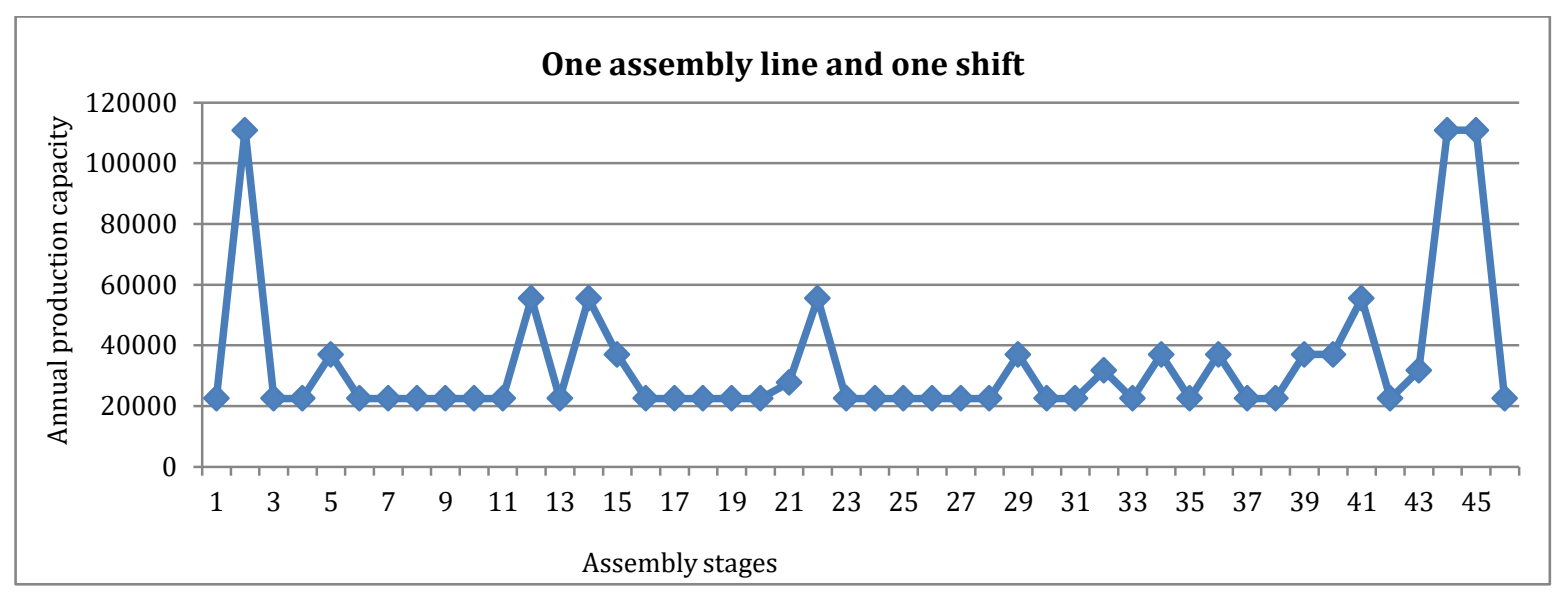

Figure 14: Annual assembly capacity of improved system 
To test the assembly process layout needs 61 workers. The test was performed on the assembly stages. The operator finished time was all less than the specified time.

\section{B. Improvement of assembly cost}

The number of workers in assembly factory is 24 . The annual payment for salary of the workers is 314640 ETB. Therefore, average annual payment for one worker is 13110 ETB. The number of workers needed to work the factory in all its capacity without improving the recommended works and the designed process layout is 48. However, in new improved system of assembly, the required number of workers is 61.

Taking the stage that needs longest time (bolt setting needs $30 \mathrm{~min}$ ) for old assembly system, the annual capacity of the factory is 3430 . Taking the stage that needs longest time that is 5 min for improved assembly system, the annual capacity of the factory is 20580.

The productivity is of the old assembly system is 71.5 piece per single worker per year. But the productivity is of improved assembly system is 327 piece per single worker per year.

The productivity in terms of cost considering annual salary of the workers, assembly cost for one piece in old system is 183 ETB. But in improved system is $39 \mathrm{ETB}$.

In assembly of the Kalashnikov there are different accessories to be used. The accessories equipments of assembly factory and their respective cost are listed in Table 8 given below.

Table 8: Equipment and their cost in assembly factory

\begin{tabular}{|c|c|c|c|c|c|c|c|c|c|}
\hline Item & Description & Model & Make & Location & Qty & $\mathrm{cf}$ & Grc(Birr) & Drv(birr) & $\begin{array}{c}203 \\
\text { Dep.Value }\end{array}$ \\
\hline 1 & bench drilling & $1--12$ & D.P.R.K & 8.A--1--1 & 1 & 0.45 & 6000 & 2700 & 270 \\
\hline 2 & hydro power press & TON5-CC & ITALY & 8.A--1--2 & 1 & 0.5 & 15000 & 7500 & 750 \\
\hline 3 & 2spindle pedestal drilling & TRAPANI ROSA & ITALY & 8.A--1--3 & 1 & 0.5 & 30000 & 15000 & 1500 \\
\hline 4 & polishing & 71--800 & D.P.R.K & 8.A--1--4 & 1 & 0.5 & 8000 & 4000 & 400 \\
\hline 5 & 2spindle pedestal drilling & TRAPANI ROSA & ITALY & 8.A--1--5 & 1 & 0.5 & 30000 & 15000 & 1500 \\
\hline 6 & 1spindle bench drilling & $1--12$ & D.P.R.K & 8.A--1--6 & 1 & 0.45 & 6000 & 2700 & 270 \\
\hline 7 & Tool grinding & $200-1$ & D.P.R.K & 8.A--1--7 & 1 & 0.5 & 12000 & 6000 & 600 \\
\hline 8 & 3spindle bench drilling & $3--12$ & D.P.R.K & 8.A--1--8 & & 0.45 & 16000 & 7200 & 720 \\
\hline 9 & 3Spindle bench drilling & $3--12$ & D.P.R.K & 8.A--1--9 & 1 & 0.45 & 16000 & 7200 & 720 \\
\hline 10 & horizontal oil press & 10 & D.P.R.K & 8.A--1--10 & 1 & 0.45 & 30000 & 13500 & 1350 \\
\hline 11 & disassembly $\mathrm{m} / \mathrm{c}$ & $11--7$ & D.P.R.K & 8.A--1--11 & 1 & 0.45 & 30000 & 13500 & 1350 \\
\hline 12 & horizontal oil press $\mathrm{m} / \mathrm{c}$ & 10 & D.P.R.K & 8.A--1--12 & 1 & 0.1 & 30000 & 3000 & 300 \\
\hline 13 & horizontal oil press $\mathrm{m} / \mathrm{c}$ & 10 & D.P.R.K & 8.A--1--13 & 1 & 0.45 & 30000 & 13500 & 1350 \\
\hline 14 & horizontal oil press $\mathrm{m} / \mathrm{c}$ & 10 & D.P.R.K & 8.A--1--14 & 1 & 0.45 & 30000 & 13500 & 1350 \\
\hline 15 & keyway milling & $\begin{array}{l}\text { KIRLOSKARVAD } \\
\text { I }\end{array}$ & INDIA & 8.A--1--15 & 1 & 0.5 & 30000 & 15000 & 1500 \\
\hline 16 & 2Spindle pedestal drilling & Tranpani ROSA & ITALY & 8.A--1--16 & 1 & 0.45 & 30000 & 13500 & 1350 \\
\hline 17 & pistion assembly & $43-1$ & D.P.R.K & 8.A--1--17 & 1 & 0.45 & 10000 & 4500 & 450 \\
\hline 18 & buff grinding & $9-300$ & D.P.R.K & 8.A--2--1 & 1 & 0.5 & 12000 & 6000 & 600 \\
\hline 19 & 2Spindle bench drilling & $1--12$ & D.P.R.K & $8 . A--2--2$ & 1 & 0.4 & 12000 & 4800 & 480 \\
\hline 20 & pistion frame assembly & $13-1$ & D.P.R.K & 8.A--2--3 & 1 & 0.6 & 10000 & 6000 & 600 \\
\hline 21 & barrel cleaning & 3 & D.P.R.K & 8.A--2--4 & 1 & 0.5 & 30000 & 15000 & 1500 \\
\hline 22 & polishing & $71-2-564$ & D.P.R.K & 8.A--2--5 & 1 & 0.5 & 8000 & 4000 & 400 \\
\hline 23 & polishing & $71-2-440$ & D.P.R.K & 8.A--2--6 & 1 & 0.5 & 8000 & 4000 & 400 \\
\hline 24 & polishing & $71-2800$ & D.P.R.K & 8.A--2--7 & 1 & 0.5 & 8000 & 4000 & 400 \\
\hline 25 & oil pressing & 10 & D.P.R.K & 8.A--2--8 & 1 & 0.45 & 30000 & 13500 & 1350 \\
\hline 26 & disassembly $\mathrm{m} / \mathrm{c}$ & $48-1$ & D.P.R.K & 8.A--2--9 & 1 & 0.5 & 30000 & 15000 & 1500 \\
\hline 27 & compressed jig & & D.P.R.K & 8.A--2--10 & 1 & 0.65 & 10000 & 6500 & 650 \\
\hline 28 & pantho-graph(copying) & 4-Jul & D.P.R.K & 8.B--1--1 & 1 & 0.6 & 15000 & 9000 & 900 \\
\hline 29 & 4Spindle bench drilling & 12-Apr & D.P.R.K & 8.B--1--2 & 1 & 0.45 & 22000 & 9900 & 990 \\
\hline 30 & pedestal drilling & VS-32B & U.S.S.R & 8.B--1--3 & 1 & 0.6 & 18000 & 10800 & 1080 \\
\hline 31 & hydro power press & Ton.25-CC & ITALY & 8.B--1--4 & 1 & 0.6 & 35000 & 21000 & 2100 \\
\hline 32 & circular grinding & $71-200$ & D.P.R.K & 8.B--1--5 & 1 & 0.55 & 10000 & 5500 & 550 \\
\hline 33 & tool grinding 9polisher) & $200-1$ & D.P.R.K & 8.B--1--6 & 1 & 0.55 & 8000 & 4400 & 440 \\
\hline 34 & buff grinding & $9-300$ & ITALY & 8.B--1--7 & 1 & 0.55 & 12000 & 6600 & 660 \\
\hline 35 & buff grinding & $9-250$ & D.P.R.K & 8.B--1--8 & 1 & 0.55 & 12000 & 6600 & 660 \\
\hline 36 & copy milling & Mohu-105 & D.P.R.K & 8.B--1--9 & 1 & 0.6 & 350000 & 210000 & 21000 \\
\hline 37 & manual press & & D.P.R.K & 8.B--1--10 & 1 & 0.65 & 5000 & 3250 & 325 \\
\hline 38 & Hoiste & RV2.1 & & 8.B--1--11 & 1 & 0.4 & 10000 & 4000 & 400 \\
\hline \multicolumn{8}{|c|}{ Total } & 527150 & \\
\hline
\end{tabular}

There are 38 machines (shown in Table 8 given above) and equipments in assembly factory. Each machineries and equipments, there is coefficient factor (cf) given to the accessory based on the current capacity of the accessory. So taking the dry value and average of 15 years life time for the current assembly system and 5 years for improved system, the component assembly cost due to the accessory it used to be assembled is 
estimated as follows. $30 \%$ of their dry value is assumed cost of maintenance of the equipments.

The assembly cost due to the equipment for current system

Total components to be assembled in average life time $=51450$

Assembly cost due to the equipment value = sum of dry cost/total components assembled

Assembly cost due to the equipment value $=13 \mathrm{ETB}$

The assembly cost due to the equipment for improved system

Total components to be assembled in average life time $=102900$

Assembly cost due to the equipment value = sum of dry cost/total components assembled

Assembly cost due to the equipment value $=7 \mathrm{ETB}$

Cost of power consumption has also considered. There is not separated controller of power in assembly factory. The power controller of assembly room is with some part of machining factory and administrative office. Therefore, the average monthly power consumption for assembly room has taken as $40 \%$ of total reading. The average monthly reading to assembly average of 190 components is 33554 ETB (Ethiopian Birr).

Power consumption $=13422$

Cost of single component due to power consumption $=$ 71 ETB

So total assembly cost for current system is $=267$ ETB

Total assembly cost for improved system is $=116 \mathrm{ETB}$

\section{Conclusions}

The parts that are wasted due crack are foresight, gas chamber and breech block. Result of crack test result confirms the most cracking piece is foresight. Coloring is the process in which most crack is observed. In machining no problem is observed. In fact the stress concentration in previous process can be cause of crack in assembly and recoloring.

Total time taken from entrance to exit for the components in assembly factory using current assembly process is 365 minutes. From this time, there will be reduction of 93 minutes by introducing the designed process assembly layout. There will be also reduction of 108 minutes of assembly time by improving the recommended manufacturing systems, assembly equipments and facilities.
Result of improvement for assembly time confirms that the annual capacity of all assembly steps are 20580 and above. Minimum annual capacity for improved system is less than the planed 30,000. Taking the stage that needs longest time (bolt setting needs $30 \mathrm{~min}$ ) for old assembly system, the annual capacity of the factory is 3430 . Taking the stage that needs longest time that is 5 min for improved assembly system, the annual capacity of the factory is 20580 .

The number of workers in assembly factory is 24 . The annual payment for salary of the workers is 314640 ETB. Therefore, average annual payment for one worker is 13110 ETB. The number of workers needed to work the factory in all its capacity without improving the recommended works and the designed process layout is 48. However, in new improved system of assembly, the required number of workers is 61.

The productivity is of the old assembly system is 71.5 piece per single worker per year which was improved by 327 piece per single worker per year in new assembly system. The productivity in terms of cost considering annual salary of the workers, assembly cost for one piece in old system is 183 ETB, whereas for the improved system is $39 \mathrm{ETB}$. Annual production capacity will increase from 3430 to 20580.

Average Power consumption costs were also compared for current and improved assembly system. Power consumption assembly cost for current system 267 ETB is much higher than 116 ETB cost of improved system.

\section{Acknowledgement}

The authors wish to express their gratitude to the Mekelle University, Ethiopia, for their financial support

\section{References}

S.S.Kuber (1990), 'Productivity improvement in plant by using systematic layout planning (SLP) of medium scale industry', IACSIT International Journal of Engineering and Technology, 3(4).

Mark Allington (2006), 'Factory layout principles', UK-RF Closed nuclear cities partnership.

Amir J. Khan (2013), 'Designing facilities layout for small and medium enterprises', International journal of Engineering research and General science, 1(2).

Mahendra Singh (2012), 'Innovative practices in facility layout planning', International journal of Marketing, Financial services \& management research, 1(12).

Bimandas(2014), 'Applying lean manufacturing system to improving productivity of air conditioning coil manufacturing', published in international journal of advance manufacturing technology.

Maskell, B, Kennedy, F.A. (2007), why do we need lean accounting and how does it work, The journal of corporation \& finance, pp5973.

Almstrom, P, Kinnander, A. (2007), Productivity Potential Assessment of the Swedish Manufacturing Industry.Swedish Production Symposium, pp1-8.

Daniel E. Whitney (2004), Mechanical Assemblies Their Design, Manufacture, and Role in Product Development, Massachusetts Institute of Technology.

Geoffrey Boothroyd (2005), assembly automation and product design, second edition.

Boothroyd Dewhurst (2002), Product Design for Manufacture and Assembly, first edition, Wakefield Rhode Island.

P. R. Olsen, W. E. Sasserand D. D. Wyckoff (1978), Management of Service Operations, pp 95-96.

Lee Peterman (2011), www. kalypso. Com 